\title{
Kolon poliplerinin boyut, lokalizasyon ve histopatolojkk yapılarının değerlendirilmesi
}

\author{
Evaluation of size, localization and histopathologic structures of colonic polyps
}

\author{
Hüseyin KORKMAZ ${ }^{1}$, İsmail Can KENDIR², Özgül AKKAYA \\ Selçuk Üniversitesi Tip Fakültesi ${ }^{1}$ Gastroenteroloji Bilim Dahı ${ }^{21 c ̧ ~ H a s t a l ı l a n ~ A n a b i l i m ~ D a l ı ~}{ }^{3}$ Endoskopi Ünitesi, Konya
}

Giriş ve Amaç: Kolonoskopi sırasında saptanan poliplerin, potansiyel kanser riski nedeniyle çıkartılması ve patolojik tanısının konması önerilmektedir. Çalışmadaki amacımız merkezimizde çeşitli nedenlerle yapılan kolonoskopi sonucunda saptanan poliplerin prevalans, lokalizasyon ve boyutlan ile birlikte histopatolojik sonuçlarını ortaya koymaktır. Gereç ve Yöntem: Selçuk Üniversitesi Tıp Fakültesi Gastroenteroloji Bilim Dalı Endoskopi Ünitesi'nde Kasım-2011 ile Aralık-2014 arasındaki kolonoskopi raporları endoskopi arşiv sisteminden retrospektif olarak tarandı. Yerleșim özellikleri ve histopatolojik tiplerine göre polipler kaydedildi. Bulgular: Kolonoskopi raporlarnna göre 304 hastada (\%14.4) toplam 360 adet polip tespit edildi. Hastaların 189'u erkek (\%62.1), 115’i kadın (\%37.8) idi. Yaş dağılımı 18-90 yıl arasında değişmekte iken, yaş ortalaması 57.4 yıl ve ortalama boyut $7 \mathrm{~mm}$ olarak saptand1. Kolon poliplerinin büyük kısminin rektumda 136 (\%37.7) oldukları tespit edildi. Poliplerde histopatolojik tip açısından en büyük hasta grubunu 242 (\%67.2) olgu ile tübüler adenom oluştururken, diğer neoplastik özellikte olan poliplerin 23 tanesi (\%6.4) tübülovillöz adenom, 3 tanesi de $(\% 0,8)$ villöz adenom olarak saptandı. Sonuç: Bu çalışmada endoskopi ünitemizde yaklaşık 3 sene boyunca çeşitli nedenlerle kolonoskopi yapılan hastalarımızdaki kolon poliplerinin prevalansı, lokalizasyonu ve histolojik sonuçları ortaya konmuştur. Çalışmamızdaki tüm sonuçların genel olarak literatür ile uyumlu olduğu gözlendi.

Anahtar kelimeler: Kolon polipleri, lokalizasyon, adenomatöz polip, histopatolojik tip

\section{GİRİŞ}

Kolorektal polipler, mukoza veya submukoza epitelinden köken alan, barsak lümeni içine doğru çıkıntı yapabilen ve kitle oluşturan proliferatif lezyonlardır. Polipler şekline (saplı, sapsız vs), sayısına, boyutuna, yerleşim yerine, genel görünümlerine ve histolojik özelliklerine göre tanımlanabilmektedirler (1). Kolorektal polipler histolojik özelliklerine göre non-neoplastik polipler (hiperplastik, hamartomatöz, inflamatuvar polipler vs.) ve neoplastik polipler (adenomlar, karsinomlar v.s) olarak sinıflandırılmaktadır (Tablo 1) (1-3). Kolonoskopi sırasında saptanan poliplerin, özellikle de neoplastik poliplerin, potansiyel kanser riski taşımalarından dolayı, çıkartılmaları önerilmektedir. Çıkartılan poliplerin patolojik tanısının konması ve bu tanıya göre hastaların belirli bir takip programına alınmasının gerekebileceği belirtilmektedir. Tübüler, villöz ve tübülovillöz adenomlar olarak üç kategoride tanımlanan adenomatöz polipler hafif veya şiddetli formda displazi

Korkmaz H, Kendir IC, Akkaya Ö. Evaluation of size, localization and histopathologic structures of colonic polyps, Endoscopy Gastrointestinal 2016;(24):13-17.
Background and Aims: Removal of polyps detected during colonoscopy and establishment of the pathological diagnosis are recommended because of their potential cancer risk. In this study, we aimed to determine the prevalence, size and localization of polyps and their histopathological results in patients undergoing colonoscopy for various reasons in our endoscopy unit. Materials and Methods: Colonoscopy reports between November- 2011 and December- 2014 were retrospectively reviewed from the endoscopy archive system in Selcuk University, Endoscopy Unit, Department of Gastroenterology. Polyps were noted according to their localization and histopathologic types. Results: According to the colonoscopy reports, a total of 360 polyps (14.4\%) were detected in 304 patients. 189 of the patients (62.1\%) were male and $115(37.8 \%)$ were female and their mean age was 57.4 years. The mean diameter of the polyps was $7 \mathrm{~mm}$. Colonic polyps were most commonly seen in the rectum with $136(37.7 \%)$ polyps. Of the polyps with neoplastic characteristics, 242 (67.2 \%) were tubular adenomas, 23 (6.4\%) tubulovillous adenomas, and $3(0.8 \%)$ villous adenomas. Conclusions: In this study, the prevalence, localization and histopathological findings of colon polyp types over an approximately three-year period was revealed in patients undergoing colonoscopy for various reasons in our endoscopy unit, our results were found to be similar to those reported in the literature.

Keywords: Colonic polyps, histologic types, localization, adenomatous polyp

içerebilirler. Tübüler adenomlar genellikle küçüktür ve hafif derecede displazi gösterirlerken, polip çapı arttıkça ve villöz yapıda olan adenomlarda displazi oranı artmaktadır. Tübüler adenomlarda \%88 hafif, \%8 orta, \%4 şiddetli displazi gözlenebilirken, tübülovillöz adenomlarda \%58 hafif, \%26 orta, $\% 16$ şiddetli displazi gözlenebiliyor. Villöz adenomlarda ise \%41 hafif, \%38 orta, \%21 şiddetli displazi görülmektedir $(2,3)$. Non-neoplastik poliplerden olan inflamatuvar polipler, iltihabi barsak hastalıkları gibi durumlarda görülen kronik inflamasyona yanıt olarak gelişen poliplerdir. Çoğu rektumda görülür, çapları 1-3 cm arasında değişmektedir. Non-neoplastik poliplerin en sık görülen türü ise hiperplastik poliplerdir ve karakteristik olarak genellikle sesil ve 5 mm'den küçük poliplerdir. Büyük olan polipler saplı olabilir ve özellikle distal kolon ve rektumda görülürler $(1,3)$. Kolonoskopi ve otopsi çalışmalarında saptanan poliplerin sıklığı bölgesel ve 
toplumsal farklılıklar göstermektedir. Bu çalışmadaki amacımız, gastroenteroloji bölümümüzde çeşitli nedenlerle yapılan kolonoskopilerde saptanan poliplerin prevalans, tip, boyut ve histopatolojik özelliklerini dökümante etmekti.

\section{GEREC ve YÖNTEM}

Selçuk Üniversitesi Tıp Fakültesi Gastroenteroloji Bilim Dalı Endoskopi Ünitesi'nde Kasım-2011 ile Aralık-2014 arasındaki kolonoskopi raporları endoskopi arşiv sisteminden retrospektif olarak tarandı. Belirgin tıkayıcı lezyonu olan, 10'dan fazla polip görülen hastalar ile inflamatuvar barsak hastalığı olan hastalar değerlendirilme dişı tutuldu. Toplam 2.100 kolonoskopik işlemde, 304 adet kolonunda polip olan olgu retrospektif olarak değerlendirildi. Poliplerin yerlessim yerleri; rektum, sigmoid kolon, inen kolon, transvers kolon, çıan kolon ve çekum olmak üzere bölgelere ayrılarak, polip büyüklükleri ile birlikte kaydedildi. Poliplerin hematoksilen-eozin ile boyanmış kesitleri gözden geçirildi ve histopatolojik tanilar taranarak kaydedildi.

Çalışma Helsinki Deklerasyonu 2008 prensiplerine uygun olarak yürütüldü. İstatistiksel değerlendirmede SPSS 15 Word paketi kullanıldı. Değişkenlerin karşılaştırılmasında Ki kare ve Mann Whitney testleri kullanıldı. $\mathrm{P}<0.05$ değeri istatistiksel olarak anlamlı kabul edildi.

\section{BULGULAR}

Çalışmaya alınan, kolonoskopi yapılmış 2.100 hastanın 304 tanesinde (\%14,4), 360 adet polip tespit edildi. Hastalarin 189'u (\% 62.1) erkek, 115'i (\%37.8) kadındı. Hastaların yaş dağılımı 18-90 yıl arasında değişmekte olup, yaş ortalaması 57.4 yl olarak saptandı. Ortalama polip boyutu $7 \mathrm{~mm}$ iken, poliplerin 270 tanesinin (\%75) boyutu 1 cm'in altinda, 90 tanesinin (\%25) boyu da 1 cm'in üstünde tespit edildi. Poliplerin kolondaki lokalizasyon ve cinsiyete göre dağılımı ile ortalama boyutları Tablo 2'de özetlenmiştir. Kolondaki polipler erkeklerde daha sik görülürken, lokalizasyona göre polip boyutları arasında fark izlenmedi ( $p>0.05)$. Ortalama polip boyutunun en yüksek olduğu kolon kısmı 8.7 mm ile sigma iken en düşük olduğu kolon kısmı ise $6.1 \mathrm{~mm}$ polip boyutu ile çekum olarak saptandı (Tablo 2). Kolon polipleri en yoğun olarak 136 (\%37.7) tane ile rektumda gözlenirken, en az yoğunlukta gözlendiği kolon bölümü ise 22 tane (\%6.2) ile çekum idi (Tablo 2).

Kolonda tespit edilen poliplerin histopatolojik inceleme sonuçları Tablo 3'te özetlenmiştir. Histopatolojik tipleri açısından en büyük polip grubunu, 242 (\%67.2) polip ile tübüler adenom oluştururken, bunu siklık sırasına göre 45 (\%12.5) polip ile hiperplastik polip takip etmekteydi. Poliplerden 2

Tablo 1. Kolorektal poliplerin histopatolojik sinıflandırlması

\begin{tabular}{|c|c|c|}
\hline Neoplastik Mukozal Lezyonlar & Non-Neoplastik Mukozal Lezyonlar & Submukozal Lezyonlar \\
\hline Benign (adenoma) & Hiperplastik (metaplastik) polip & Kolitis sistika profunda \\
\hline Tubuler adenom & $\begin{array}{l}\text { Normal epitelyum } \\
\text { (polipoid görünüm-mukozal polipler) }\end{array}$ & Pnömatozis sistoides intestinalis \\
\hline Tubulovillöz adenom & Juvenil polip (retansiyon polibi) & Lenfoid polipler \\
\hline Villöz adenom & Peutz-Jegher polip & Lipoma \\
\hline Malign (karsinoma) & Inflamatuvar polipler & Metastatik neoplazmlar \\
\hline Noninvaziv karsinom & & Diğer \\
\hline \multicolumn{3}{|l|}{ Karsinoma insitu } \\
\hline \multicolumn{3}{|l|}{ Intramukozal karsinom } \\
\hline Invaziv karsinom & & \\
\hline
\end{tabular}

Tablo 2. Kolondaki poliplerin lokalizasyon, cinsiyet dağılımı ve ortalama boyutları

\begin{tabular}{lcccc}
\hline Lokalizasyon & Sayı (n), (\%) & Kadın, $\mathbf{n}(\%)$ & Erkek, n (\%) & Ortalama Boyut (mm) \\
\hline Rektum & $136(37.7)$ & $37(27.2)$ & $99(72.7)$ & 6.6 \\
\hline Sigmoid kolon & $51(14.2)$ & $16(31.3)$ & $35(68.6)$ & 8.7 \\
Inen kolon & $62(17.4)$ & $19(30.6)$ & $43(69.3)$ & 6.9 \\
Transvers kolon & $61(16.9)$ & $13(21.3)$ & $48(78.6)$ & 7.2 \\
\hline Çıan kolon & $28(7.6)$ & $4(17.8)$ & $23(82.1)$ & 6.1 \\
Çekum & $22(6.2)$ & $8(36.3)$ & $14(63.6)$ & 6.3
\end{tabular}




$\begin{array}{lcc}\text { Tablo 3. Kolon poliplerinin histopatolojik sonuçları } \\ \text { Patoloji } & \text { Sayı } & \text { Yüzde (\%) } \\ \text { Mukozal doku } & 24 & 6.6 \\ \text { Hiperplastik polip } & 45 & 12.5 \\ \text { Tübüler adenom } & 242 & 67.2 \\ \text { Tübülovillöz adenom } & 23 & 6.4 \\ \text { Villöz adenom } & 3 & 0.8 \\ \text { Serrated adenom } & 4 & 1.1 \\ \text { Adeno Ca } & 2 & 0.5 \\ \text { Juvenil polip } & 2 & 0.5 \\ \text { Lipom } & 4 & 1.1 \\ \text { Inflamatuvar polip } & 11 & 3.3\end{array}$

tanesinin $(\% 0,5)$ patoloji sonucunda adenokarsinom tespit edilirken, incelenen poliplerin 24 tanesinin (\%6.6) patoloji sonucu mukozal doku idi. Toplam 268 (\% 74.4) tane neoplastik özellikte polip tespit edildi. Bu neoplastik poliplerin 242 tanesini (\%67.2) tübüler adenom, 23 tanesini (\%6.4) tübülovillöz adenom, 3 tanesini de (\%0.8) villöz adenomlar oluşturmaktaydı (Tablo 3).

Neoplastik poliplerin kolondaki lokalizasyonları ve displazi varlığ Tablo 4'te gösterilmektedir. Bu poliplerden 194 (\%72.3) tanesinde displazi yok iken, 56 (\%20.8) tanesinde düşük dereceli, 18 (\%6.7) tanesinde yüksek dereceli displazi varlığı mevcuttu. Tüm kolon polipleri klyaslandığında ise displazi oranı \%14.4 olarak saptandı. Histopatolojik olarak değerlendirildiğinde, tübüler adenom kolonun tüm kısımlarında en sık saptanan polip tipi olarak gözlendi.

\section{TARTISMA}

Kolon polipleri görünüm olarak saplı veya sapsız (sesil), tek veya birden fazla sayıda, mukozayla aynı veya farklı renkte olabilirler. Sayıca en fazla rektosigmoid bölgede olabilmekteyken ve çekuma doğru gidildikçe görülme sıklıkları azalmaktadır. Poliplerin çoğu genellikle asemptomatik olmakla birlikte, en önemli klinik belirtileri rektal kanamadır. Bu kanama aşikar ya da dışkıda gizli kanama olarak tespit edilebilmektedir. Büyük polipler, nadiren kabızlık, gaita şeklinde değişiklik, karın ağrısı ve obstrüksiyona neden olabilirler. Çok nadir olarak da özellikle villöz polipler hipokalemi ve hipoalbüminemi ile karakterize sekretuvar tipte ishale neden olabileceği bildirilmektedir.(4)

Kolorektal poliplerin çoğu neoplastik polipler grubundan olan adenomatöz poliplerdir ve tüm kolon poliplerinin yaklaşık 2/3'ünü oluştururlar. Bu adenomatöz poliplerin \%8086'sını tübüler adenomlar, \%3-16'sını villöz adenomlar ve \%8-16'sını tübülovillöz adenomlar oluşturmaktadır $(2,5)$.

Adenomatoz poliplerin prevalansı çeşitlilik göstermekle birlikte özellikle ileri yaşlarda poliplerin görülme sıklı̆̆ı, büyüklügü ve displazi gelişme oranı artmaktadır $(6,7)$. Ayrıca erkek cinsiyeti ve abdominal obezite de adenomatöz polipler için risk faktörleri olarak belirtilmektedir $(6,8,9)$. Literatürde, kolorektal poliplerin sıklığ1 erkeklerde \%53-59, kadınlarda \%40-46 olarak bildirilmektedir $(10,11)$.

Ülkemizde kolon poliplerinin prevalansını belirleyen büyük ölçekte ve geniş çaplı bir çalışma halen mevcut değildir. Son yıllarda birkaç merkezde yapılan çalışmalarda, ortalama 50 yaş civarı popülasyonda saptanan kolon polip yüzdesinin yaklaşık \% 15-22.6 civarında olduğu ile birlikte poliplerin erkeklerde ve sol kolonda daha fazla tespit edildiği bildirilmiştir (11-13).

Bizim çalışmamızda polip saptanan hasta yüzdesi \%14.4 idi. $\mathrm{Bu}$ hastaların yaş ortalaması 57.4 yıl olup, daha önceki çalışmalara benzer şekilde polip sıklığı erkeklerde (\%62.1) kadınlardan (\%37.8) fazla olarak saptandı. Yine bizim çalışmamıda kolorektal polipler \%37.7 rektumda, \%14.2 sigmoid

Tablo 4. Adenomatöz poliplerin lokalizasyonuna göre tiplerinin ve displazi derecelerinin değerlendirilmesi

\begin{tabular}{|c|c|c|c|c|c|c|c|c|c|c|c|c|}
\hline \multirow[t]{2}{*}{ Lokalizasyon } & \multicolumn{4}{|c|}{ Tübüler Adenom } & \multicolumn{4}{|c|}{ Tübülovillöz Adenom } & \multicolumn{4}{|c|}{ Villöz Adenom } \\
\hline & $\mathrm{n},(\%)$ & $\begin{array}{c}\text { Diplazi } \\
\text { yok, n (\%) }\end{array}$ & $\begin{array}{c}\text { Düşük } \\
\text { dereceli } \\
\text { displazi } \\
\text { n, (\%) }\end{array}$ & $\begin{array}{c}\text { Yüksek } \\
\text { dereceli } \\
\text { displazi } \\
\text { n, (\%) }\end{array}$ & $\mathrm{n},(\%)$ & $\begin{array}{c}\text { Diplazi } \\
\text { yok, } \\
\text { n, (\%) }\end{array}$ & $\begin{array}{c}\text { Düşük } \\
\text { dereceli } \\
\text { displazi } \\
\text { n, (\%) }\end{array}$ & $\begin{array}{c}\text { Yüksek } \\
\text { dereceli } \\
\text { displazi } \\
\text { n, (\%) }\end{array}$ & $\mathrm{n},(\%)$ & $\begin{array}{l}\text { Diplazi } \\
\text { yok, } \\
\text { n, (\%) }\end{array}$ & $\begin{array}{c}\text { Düşük } \\
\text { dereceli } \\
\text { displazi } \\
\text { n, (\%) }\end{array}$ & $\begin{array}{c}\text { Yüksek } \\
\text { dereceli } \\
\text { displazi } \\
\text { n,(\%) }\end{array}$ \\
\hline Rektum & $67(49.2)$ & $49(73.1)$ & $13(19.4)$ & $5(7.4)$ & $8(5.8)$ & $5(75.0)$ & $2(25.0)$ & $1(12.5)$ & 0 & 0 & 0 & 0 \\
\hline Inen kolon & $53(85.4)$ & $37(69.8)$ & $12(22.6)$ & $4(7.5)$ & $3(4.8)$ & $2(66.6)$ & $1(33.3)$ & 0 & 0 & 0 & 0 & 0 \\
\hline Sigmoid kolon & $36(70.5)$ & $27(75.0)$ & $6(16.6)$ & $3(8.3)$ & $7(13.7)$ & $4(57.1)$ & $2(28.5)$ & $1(14.2)$ & $1(1.9)$ & $1(100)$ & 0 & 0 \\
\hline Transvers kolon & $51(83.6)$ & $39(76.4)$ & $10(19.6)$ & $2(3.9)$ & $2(3.1)$ & $1(50.0)$ & $1(50.0)$ & 0 & $1(1.6)$ & 0 & $1(100)$ & 0 \\
\hline Çekum & $17(77.2)$ & $12(70.5)$ & $4(23.5)$ & $1(5.8)$ & $1(5.8)$ & $1(100)$ & 0 & 0 & 0 & 0 & 0 & 0 \\
\hline Çıkan kolon & $18(64.2)$ & $13(72.2)$ & $4(22.2)$ & $1(5.5)$ & $2(11.1)$ & $2(100)$ & 0 & 0 & $1(1.6)$ & $1(100)$ & 0 & 0 \\
\hline
\end{tabular}

$\mathrm{n}$, hasta sayısı 
kolonda, \%17.4 inen kolonda, \%16,9 transvers kolonda, \% 7,6 çıkan kolonda ve \%6.2 çekumda saptandı. Yapılan çalışmalarda adenomların en sık rektosigmoid kolonda yerleştiği ve poliplerin \%44'ünün kolonun distal 60 cm'lik kısmında bulunduğu bildirilmiştir $(14,15)$. Konishi ve arkadaşları 675 olguluk bir seride \%47 sigmoid kolon, \%18,7 inen kolon, \%13,6 transvers kolon, \%12,5 rektumda polip olduğunu bildirmiştir (2). Ülkemizde Eminler ve arkadaşlarının Marmara bölgesinde yaptıkları bir çalışmada; \%47.0 rektosigmoid, \%19.3 inen kolon, \%11.2 transvers kolon, \%8.5 çıkan kolon ve \%4.6 çekumda polip saptandığı bildirilmiştir (11). Yine yakın zamanda Dölek ve arkadaşlarının Çankıı bölgesinde yaptıkları çalışmada, kolondaki poliplerin \%36'sının rektumda, \%16,6'sının transvers kolonda, \%3,7'sinin çıkan kolon, \%13,3'nün inen kolon, \%5,9'nun çekum ve \%10,3'nün sigmoid kolonda bulunduğu bildirilmiştir (13). Bu sonuçlar ile karşılaştırıldığında, bizim çalışmamızdaki poliplerin kolondaki dağılımının literatür ile uyumlu olduğu görüldü.

Büyük adenomlar distal kolon segmentlerinde daha sık görülür ve adenomların çoğu 1 cm'den küçüktür. Tübüler adenomlar \%77 oranında 1 cm'den küçük, \%20 oranında 1-2 $\mathrm{cm}$, \%4 oranında $2 \mathrm{~cm}$ 'den büyüktür. Tübülovillöz adenomlar \%25 oranında 1 cm'den küçük, \%47 oranında $1-2 \mathrm{~cm}$, \%29 oranında 2 cm'den büyüktür. Villöz adenomlar \%14 oranında 1 cm'den küçük, \%26 oranında $1-2 \mathrm{~cm}$, \%60 oranında 2 cm'den büyüktür (6). Küçük polipler $5 \mathrm{~mm}$ ve daha küçük çaptaki poliplerdir. Bunlar hemen daima non-neoplastiktir. Villöz olan veya ağır displazi odağı içeren küçük poliplerin oranı \% l'den azdır $(16,17)$. Çalışmamızda ortalama polip boyutu $7 \mathrm{~mm}$ olarak saptandı ve lokalizasyona göre polip boyutları arasında istatiksel fark izlenmedi.

Tüm kolon poliplerinin yaklaşı \% 75 'ini adenomlar oluşturmakta olup, hemen bütün kolorektal kanserler adenom zemininde gelişmektedir. Ancak adenomların çok küçük bir yüzdesi kansere dönüşmektedir (yaklaşık \%5). Yapılan çalışmalarda adenomdan kanser gelişme süreci 7-10 yll arasında verilmektedir. Özellikle displazi derecesi yüksek adenomlarda kansere progresyon riski daha yüksektir $(11,18)$. Villöz histoloji, artmış polip boyutu ve polip sayısında artış; kanser için diğer risk faktörleri olarak tanımlanmıştır (18). Tübüler adenomlarda malignite gelişme riski daha azken, villöz ve tübülovillöz adenomlarda bu risk \%33 olarak bildirilmektedir $(13,18)$. Adenomlar çıkarılsa bile, çıkarıldıktanl yıl sonra $\% 5-15,5$ yll sonra \%20-15 ve 15 yll sonra \%50 oraninda rekürrens adenomların olabileceği belirtilmektedir (13). Bu nedenle çeşitli ulusal ya da uluslar arası kuruluşlar, polipin büyüklüğü, histopatolojisi ve displazi derecesine göre belirli takip programları önermektedir.

Çeşitli hasta sayıları ile yapılan çalışmalarda kolonda tübüler adenomun \%64.8 - 80.7, tübülovillöz adenomun \%7.2-16.4 ve villöz adenomun \%0.5-11.2 oranında saptandığı bildirilmiştir $(2,10,19)$. Bizim çalışmamızda toplam adenom yüzdesi \%74.4 olup, bunların \%67.2'si tübüler adenom, \%6.4'ü tübülovillöz adenom ve \%0.8'i villöz adenom olarak saptand. Displazi yüzdesi ise $\% 18,9$ olarak tespit edilirken $\% 0.5$ oranında ise çıkartılan polip sonuçları adenokarsinom olarak saptandı. Saptanan bu sonuçlarımız genelde literatür bulguları ile uyumluydu.

Sonuç olarak bu çalışmada Iç Anadolu bölgemizin geniş bir kesimine hizmet veren endoskopi ünitemizde çeşitli nedenlerle kolonoskopi yapilan hastalardaki kolon polip tipleri, prevalansı, lokalizasyonları, büyüklükleri ortaya konmuştur. Aynı zamanda neoplastik özellikte olan adenomatöz poliplerin de histopatolojik özellikleri incelenmiş ve displazi yüzdeleri verilmiştir. Bu çalışmada da görüldüğü gibi kanser öncüsü olabilen poliplerin bölgemizde de literatüre yakın oranlarda tespit edilmesi nedeniyle ülkemiz için kolon tarama programlarının geliştirilmesi ve toplumun bilgilendirilmesi gerektiği açıktır. Bununla birlikte özellikle displazi saptanan olgulardaki prognozun ortaya konması için daha geniş çapta ve prospektif çalışmalara ihtiyaç vardır.

\section{KAYNAKLAR}

1. Itzkowitz SH, Potack J. Colonic polyps and polyposis syndromes. In Sleisenger MH, Fordtran JS, (Eds). Sleisenger and Fordtran's Gastrointestinal and Liver Disease. 8 th ed. Philedeplhia. Saunders. 2006; 2713-36.

2. Konishi F, Morson BC. Pathology of colorectal adenomas: A colonoscopic survey. J Clin Pathol 1982;35:830-41

3. Boland CR, Itzkowitz SH, Kim YS. Colonic polyps and gastrointestinal polyposis syndromes. Gastrointestinal disease, Sleisenger MH, Fordran JSS, Philadelphia, WB Saunders Company 1989;2:1483-518.

4. Winawer SJ, Zauber AG, Fletcher RH, et al, US Multi-Society Task Force on Colorectal Cancer; American Cancer Society. Guidelines for colonoscopy surveillance after polypectomy: a consensus update by the US Multi-Society Task Force on Colorectal Cancer and the American Cancer Society. Gastroenterology 2006;130:1872-85.
5. O'Brien MJ, Winaver SJ, Zauber AG, et al. The National Polyp Study: Patient and polyp characteristics associated with high-grade dysplasia in colorectal adenomas. Gastroenterology 1990;98:371-9.

6. Williams AR, Balasoorriya BAW, Day DW. Polyp and cancer of the large bovel: A necropsy study in Liverpool. Gut 1982;23:835-42.

7. Vatn MH, Staisberg H. The prevalence of polyps of the large intestine in Osio: An autopsy study. Cancer 1982;49:819-25.

8. Nam SY, Kim BC, Han KS, et al. Abdominal visceral adipose tissue predicts risk of colorectal adenoma in both sexes. Clin Gastroenterol Hepatol 2010;8:443-50

9. Nguyen SP, Bent S, Chen YH, Terdiman JP. Gender as a risk factor for advanced neoplasia and colorectal cancer: a systematic review and meta-analysis. Clin Gastroenterol Hepatol 2009;7:676-81. 
10. Altınparmak E, Sezgin O, Parlak E, Altıntaş E. Colorectal polyps 'The Yüksek thtisas experience'. Turk J Gastroenterol 2001;12:49-52.

11. Eminler AT, Sakallı M, Irak K, et al. Gastroenteroloji ünitemizdeki kolonoskopik polipektomi sonuçlarımız. Akademik Gastroenteroloji Dergisi 2011;10:112-5.

12. Aslan S. Gastrointestinal Sistemin Polipleri In: Klinik Gastroenteroloji. Memik F. Editor. Istanbul. Nobel Tip Kitapevleri Ltd. 2004;512-29.

13. Dolek Y, Karabulur YY, Topal F, et al. Gastrointestinal poliplerin boyut, lokalizasyon ve histopatolojik tipleriyle değerlendirilmesi. Endoskopi 2013;21:31-3.

14. Bech K, Kronborg O, Fenger C. Adenomasand hyperplastic polyps in screening studies. World J Surg 1991;15:7-13.
15. Lieberman DA, Smith FW. Screening for colon malignancy with colonoscopy. Am J Gastroenterol 1991;86:946-51.

16. Granqvist S, Cabrielsson N, Sundelin P. Diminutive colonic polypsclinical significance and managemant. Endoscopy 1979;11:36-42.

17. Matek W, Guggenmoos-Holzmann I, Demling L. Follow-up of patients with colorectal adenomas. Endoscopy 1985;17:175-81.

18. Heitman SJ, Ronksley PE, Hilsden RJ, et al. Prevalence of adenomas and colorectal cancer in average risk individuals: a systematic review and meta-analysis. Clin Gastroenterol Hepatol 2009;7:1272-8.

19. Muto T, Bussey HJR, Morson BC. The evolution of cancer of the colon and rectum. Cancer 1975:36;2251-70. 